\title{
Patterns of Violent Relationships, Psychological Distress, and Marital Satisfaction in a National Sample of Men and Women
}

\author{
Stacey L. Williams ${ }^{1,3}$ and Irene Hanson Frieze ${ }^{2}$
}

\begin{abstract}
This paper examined six patterns of violent relationships (severe and mild victimization, perpetration, and mutual violence) and their associations with psychosocial outcomes in men and women $(N=3,519)$ using data from the National Comorbidity Survey. Violence patterns most frequently reported included mild and severe violence performed by both relationship partners. Some gender differences in frequency of patterns emerged. Main results showed gender differences and some similarities in associations between violence patterns and negative psychosocial outcomes. Women's victimization, regardless of severity, was more strongly related to psychosocial outcomes than men's. Yet, additional findings revealed gender similarities, with both men and women affected by mutual violence. Post hoc analyses further suggested that some individuals were satisfied and had relatively low distress, despite violence.
\end{abstract}

KEY WORDS: violence; distress; satisfaction; gender; relationships.

Traditionally, research has conceptualized violence in intimate relationships in terms of "battered women." This view of abused women being at the mercy of their abusive male partners has been widely accepted among researchers (e.g., Frieze \& Browne, 1989; Pagelow, 1981, 1984; Tjaden \& Thoennes, 1998; Walker, 1979). Battered women have been found to experience a variety of negative psychosocial and mental health consequences of this victimization (e.g., Frieze, Hymer, \& Greenberg, 1987; Frieze, 2005). But, the situation of the battered woman does not explain all of the patterns of violence that occur in couples. Studies have shown that women can be "equally violent" or display even more frequent violent acts than men toward partners (see Archer, 2000, meta-analysis). Theoretically based typologies have

\footnotetext{
${ }^{1}$ Institute for Social Research, University of Michigan, Ann Arbor, MI.

${ }^{2}$ University of Pittsburgh, Pittsburgh, PA.

${ }^{3}$ To whom correspondence should be addressed at Institute for Social Research, University of Michigan, Ann Arbor, MI 48106; e-mail: staceywg@isr.umich.edu.
}

been offered that attempt to classify different patterns of violent couple relationships (e.g., Johnson, 1995). In the present research, we attempt to provide empirical support for different patterns of couple violence based on reports of men and women about their own violence toward their partner and about the violence that they have received from their partner. We attempt to systematically examine patterns of violent relationships based on the previously acknowledged violence dimensions of mutuality and severity, and to explore some psychosocial outcomes associated with violence. Another major focus of this paper is to consider the role of gender in different patterns of violent couple relationships. We examine the possibility that men and women may experience violence victimization differently.

\section{Intimate Partner Abuse and Its Consequences}

Many studies have documented women's victimization at the hands of their intimate male partners (e.g., Browne, 1993; Frieze \& Browne, 1989; Tjaden 
\& Thoennes, 1998; White \& Kowalski, 1998; White, Smith, Koss, \& Figueredo, 2000). Some researchers estimate that over 4 million women experience violence from an intimate partner each year (Plichta, 1996). These prevalence rates are even more staggering when the potential consequences of physical violence and psychological abuse are considered. In addition to obvious physical health effects due to injury, research has shown the experience of violence to be associated with negative health perceptions and behaviors, alcohol and drug abuse, and various sexual problems (Resnick, Acierno, \& Kilpatrick, 1997). Other potential outcomes of partner violence include anger, guilt, shame, and feelings of powerlessness in the victim (Frieze et al., 1987).

Most frequently, research has shown that male partner violence is associated with psychosocial and mental health problems in women (e.g, Browne, 1993; Golding, 1999; Goodman, Koss, \& Russo, 1993; Janoff-Bulman \& Frieze, 1983; Marshall, 1999; Williams \& Mickelson, 2004). Mental health correlates of men's violence against women have involved factors such as depression, anxiety, and intense startle reactions in the women victims (Goodman et al., 1993). In fact, in a review, Golding (1999) concluded that partner violence is related to increased levels of depression and anxiety, including post-traumatic stress disorder (PTSD), in addition to many other consequences in women's lives.

Other studies have shown similar negative psychosocial outcomes in women. For example, in a recent study of newlywed couples, Testa and Leonard (2001) examined the impact of husband-to-wife violence on wives' marital and personal well-being longitudinally. After accounting for prior levels of marital and personal distress, results showed that women experienced decreases in marital satisfaction and increases in personal distress following abuse from their husbands. Studies have shown that in distressed relationships where there is husband-to-wife violence, there are fewer positives or benefits of the relationship (e.g., intimate language in its partners' communication) than in either distressed or happy non-violent others (Langhinrichsen-Rohling, Schlee, Monson, Ehrensaft, \& Heyman, 1998). Not surprisingly, researchers have found evidence for increased marital dysfunction with increases in aggressiveness in couples (Lawrence \& Bradbury, 2001).

One caveat important to consider is that variables associated with violence have been studied mostly in relation to women's victimization at the hands of male partners. This focus is reflective of the traditional conceptualization of partner violence as involving battered women who experience severely violent behaviors perpetrated by their abusive male partners. Although we do not doubt the empirical, as well as anecdotal, support for such woman battering and the negative sequelae for women, we also acknowledge work of other researchers finding that women can perpetrate violent behaviors against intimate partners. In fact, many studies have documented rates of women's violent acts at identical frequencies as that of men (e.g., Straus \& Gelles, 1988; Straus, 1999). A recent meta-analysis of over 80 research reports indicated that women report committing more frequent violent behaviors than men in intimate partnerships (Archer, 2000). The present study looks at women's abusive acts performed toward their partners in addition to men's partner violence.

Another contribution of this research is to extend our understanding of the effects of partner violence to a general population sample. Much of the research on male partner violence utilizes women presenting at shelters or court samples. Many studies of violent couples in more general populations have focused on partners who are presenting at clinics for marital therapy (e.g., Vivian \& LanghinrichsenRohling, 1994; Langhinrichsen-Rohling et al., 1998). Such samples cannot be readily generalized since the fact that they are seeking therapy implies a certain level of marital distress or discordance among these couples. Level of marital satisfaction in violent couples in the general population is unclear, particularly with regard to specific dimensions of violent relationships. The national sample we employ should allow us to examine this issue as well.

\section{Additional Considerations: Mutuality, Severity, and Gender}

Also considered in this study is if the association of psychosocial outcomes with violence depends on whether the violence is mutual or one-sided. Little research has focused on the possible negative consequences of women's violence toward their male partners or mutual violence experienced by both men and women. In a recent study that examined violent relationships based on women's reports of their own and their partners' violent and coercive acts, Swan and Snow (2003) explored psychological correlates of violent relationship types. Results of this study showed some differences in psychosocial outcomes based on whether violence was mutual or onesided; it appeared that women who were primarily 
victims or aggressors were worse off in terms of psychosocial factors than women in more mutually violent/coercive relationships. Based on theoretical arguments in line with interdependence and differential costs and rewards of relationships (e.g., Thibaut \& Kelley, 1959; Rusbult, 1983), it makes sense that individuals in mutually violent relationships might appear more satisfied than those in one-sided or asymmetric violent relationships, as there is, presumably, more of a balance in relationship power and rewards. The present study begins to examine whether or not psychosocial correlates of violence differ depending on violence mutuality between men and women.

Yet another issue to consider is whether or not severity of violence relates to reactions to mutual as well as one-sided violence. Research has shown that even more subtle forms of emotional or psychological abuse can be linked with a variety of negative adjustment-related variables (e.g., low self-esteem, rumination; Marshall, 1999). Such findings provide support for the idea that relatively low-levels of violence in intimate relationships might be associated with psychological distress or marital dissatisfaction. However, exactly how individuals experience violence of varying severity in both asymmetric and mutually violent relationships is unclear. In this research, we further examine the patterns of distress that occur with low level violence, as well as more severe violence. Severity and mutuality are considered independent correlates of outcome measures.

Overall, associations of violence with distress may depend on who is doing the violence. There may be differences in the levels of distress experienced by women and men in similarly violent relationships. Some argue that men experience battering from abusive wives and demonstrate much the same patterns as women abused by battering husbands (Migliaccio, 2002). Others have posited that even if men and women perform behaviors at the same frequency (as reported in objective questionnaires), men and women's behaviors do not have similar impact. For example, researchers have provided evidence that women are more likely to report negative sequelae (e.g., lower relationship satisfaction) following partner violence than are men (Katz, Kuffel, \& Coblentz, 2002). In a recent study of victimization and perpetration, Anderson (2002) found that when both women and their partners displayed violent behaviors, women experienced more psychological problems following their victimization than men who were victimized. These latter findings may be explained by past work showing that regardless of what actual violent acts are performed, more injury is associated with violent acts done by men to women and that women's violence is not taken seriously by men (Sinclair \& Frieze, 2002). Thus, regardless of the apparent symmetrical nature of men and women's violence, violence may in fact be asymmetrical due to the differential effects of violence on men and women in terms of injury and psychological health (e.g., Kimmel, 2002). However, it is premature to conclude as much due to the dearth of research on men as victims of violence from their female partners. In this study, we examine rates of reported violence and associations of violence with psychosocial outcomes in men and women.

To summarize, addressing the current gaps and limitations in the literature, the main goals of the present study are (1) to identify patterns of violent relationships by classifying differing dimensions of violence mutuality and severity, and to report the occurrence of these patterns in men and women from a national sample; (2) to determine whether the psychosocial outcomes of psychological distress and marital satisfaction are differentially associated with violence patterns in men and women. We have chosen to address these goals by conducting secondary analysis of data from the National Comorbidity Survey (NCS), a nationally representative sample of men and women.

\section{METHOD}

\section{Sample and Procedure}

The data came from the National Comorbidity Survey (NCS; Kessler et al., 1994), a nationwide household survey of the U.S. population between ages $15-54$, designed to produce data on the prevalence and correlates of psychiatric disorders. The sample was based on a stratified, multi-stage area probability sample of the non-institutionalized civilian population in the 48 coterminous states, with a supplemental sample of students living in campus group housing. The survey was administered faceto-face in the homes of respondents (one per household) by trained interviewers. The response rate was $82.4 \%$. A two-phase sample design was used in the NCS. In the first phase, the Part I diagnostic interview was administered to all 8,098 respondents. In the second phase, a Part II risk factor interview was administered to a probability sub-sample of 5,877 respondents. In the present study, data from individuals who were married or cohabiting with a romantic 
partner, had completed Part I and Part II of the interview, and had no missing data on the main study variables, were used in analysis $(n=3,519 ; 1,727$ men, 1,792 women). The decision to include only married or cohabiting individuals in the present analysis was based on the relationship violence questions being administered to this subset of the sample. It should be kept in mind that the NCS sample does not include both the male and female member of the same couple.

Data were weighted to adjust for variation in probabilities of selection across households and within households, and were post-stratified by means of an iterative procedure to approximate the national population distributions of the cross-classification of age, gender, race/ethnicity, marital status, education, living arrangements, region, and urbanicity as defined by the 1989 U.S. National Health Interview Survey (NHIS; U.S. Department of Health and Human Services, 1992). A comparison of the NCS sample with the NHIS shows that this sample is quite comparable to the general adult population of the United States. For example, the percentage of males $(49.8 \%)$ and females $(50.2 \%)$ in the NCS is equivalent to the national population $(49.1 \%$ and $50.9 \%$, respectively). Similarly, equivalent percentages were found for age, marital status, race, education, region, and urbanicity. See Kessler et al. (1994) for further details on the NCS sample and weighting.

\section{Measures}

\section{Sociodemographics}

Five demographic characteristics were assessed: age, education, income, employment status, and race/ethnicity. Age consisted of four categories: 1524, 25-34, 35-44, 45-54. Four categories measured education in number of completed years of formal education: $0-11,12,13-15$, and 16 or more. Income represented total family income before taxes in the year prior to the interview and was categorized into four standard groups representing "poor," "working poor," "middle," and "upper" income: \$019,999, \$20,000-34,999, \$35,000-69,999, and \$70,000 or more. Employment status was represented as a dichotomous variable, either currently employed or unemployed. Race/ethnicity was self-identified and consisted of non-Hispanic Whites, African Americans, and Hispanics. Although the NCS also assessed several other races/ethnicities (e.g., Asian,
Pacific Islander, Native American), their numbers were low and, therefore, combined into the category of "other." Because age, education, income, and race/ethnicity were categorized, for analytic purposes they were dummy coded and a reference group was chosen for each (i.e., ages 45-54, 16 or more years of education, $\$ 70,000$ or more of income, and nonHispanic Whites).

\section{Intimate Partner Violence}

Violence that respondents experienced from and perpetrated against their marital or cohabiting partners was determined using a modified version of the Conflict Tactics Scale (CTS; Straus, 1979). In the NCS, the CTS items were collapsed into three lists of violent tactics that increased in severity: threats of physical violence (e.g., threatened to hit), minor physical violence (e.g., pushed, grabbed, or shoved), and severe physical (e.g., beat up). As both partners of the couples were not interviewed in this study, respondents self-reported their own behaviors and their partners' behaviors that occur when they have disagreements in their relationship (i.e., traditional CTS directions). Specifically, respondents were first asked how often during a disagreement their spouse or partner does any of the specified acts to them, followed by their reports of perpetrating the acts, using a 4-point scale [0 never - 3 often $]$. No time frame was given for this violence, so we assume people are reporting on current levels of violence. Individuals were considered as having been in a violent relationship if they had experienced (or perpetrated) threats of violence "often," or if they experienced minor physical violence "sometimes" or "often," or experienced any severely violent act. Such criteria were invoked to better ensure that the behaviors being considered were indeed violent. We assumed that threats given rarely or sometimes may not indicate violence, especially if there is no other violence in the relationship. Similarly, minor violence such as grabbing or shoving, done rarely, may not indicate a violent relationship.

Our main goal was to classify violence patterns based on the combination of severity and mutuality, followed by examination of men and women's experience of these patterns. As a preliminary step in classifying violence groups, we began making distinctions in violence characteristics in terms of its severity and mutuality. Specifically, severity of violence was determined by whether respondents or their partners performed mild or severe violence. Mild violence was 
defined by individuals meeting criteria for threats of violence or minor physical violence, but not severe physical violence. Severe violent relationships were considered those who had met criteria for the severe physical violence list, whether or not they had mild violence. Mutuality was determined by whether or not respondents and their partners had perpetrated equal (i.e., both severe violence, both mild violence) or greater levels of violence (i.e., one severe and the other mild/nonviolent; one mild and the other nonviolent). Individuals in the former category were considered as having been in mutually violent relationships, while those in the latter category were considered in asymmetric violent relationships. We further characterized asymmetric violent relationships in terms of victimization (partner more violent) and perpetration (respondent more violent). Both men and women in the asymmetric violent relationships could, therefore, be mild or severe victims or perpetrators. Thus, six possible patterns of violent relationships resulted from our overall classification (i.e., mutually severe, mutually mild, severe victim, severe perpetrator, mild victim, mild perpetrator) and were treated as separate dichotomous variables in all analyses. Additionally, relationships could be classified as completely nonviolent.

\section{Psychosocial Variables}

We assessed the psychosocial outcomes of 30-day distress and marital satisfaction rating available in the NCS. The 30-day distress $(\alpha=.92)$ measure created for the NCS consisted of 14 items to which individuals responded with the extent to which they felt various forms of distress in the past month, using a 4-point scale [1 never-4 often]. Sample items include "How often did you worry too much about things?" Standardized mean scores were calculated, with higher scores indicative of higher levels of distress. Marital satisfaction was measured using one item which asked respondents "Overall, would you rate your (marriage/relationship) as poor, fair, good, or excellent?" Responses were coded 0-3, respectively, higher scores indicating more positive marital ratings. The two psychosocial indicators were negatively correlated $(r=-.33, p<.001)$.

\section{Analysis}

To achieve our main goal of examining associations between violence patterns and psychosocial outcomes in men and women, we conducted a series of multiple linear regression analyses. A main effects model was first conducted with the six dichotomous patterns of violence and gender entered simultaneously. Next, six interaction terms of the violence patterns by gender were entered into models predicting psychological distress and marital satisfaction to test for specific gender differences in associations. To further explicate our findings, we conducted stratified regression analyses that examined the association of violence patterns with psychosocial outcomes separately for men and women. In all analyses we statistically controlled for five demographic variables: age, education, income, employment status, and race, because these demographics significantly predicted the dependent variables in preliminary analyses. Because of the complex sample design and weighting, the Jackknife Repeated Replication method (Rust, 1985) was used to correct for the bias in standard errors. A SAS macro was employed to conduct this procedure. The resulting estimates consider both clustering and weighting of the study's design. As few men reported perpetrating severe violence ( $n=2$; shown below), significance tests for severe perpetrating men are not reported in the results that follow. We believe that information from two individuals is not sufficient to inform our research question. Because of the large sample size and multiple analyses we conducted, we took a more conservative approach by considering significant findings as those with $p<.01$.

\section{RESULTS}

\section{Occurrence of Violence Patterns}

Prior to examining variables associated with violence patterns, we identified the occurrence of the six patterns of violent relationships based on compilations of dimensions in the sample. Descriptive analyses showed that, of the total sample of men and women, $18.4 \%(N=646)$ were involved in any pattern of violent relationship. Thus the largest group was identified as nonviolent. As shown in Table I, the most frequent pattern of violent relationship was mutually mild $(5.4 \%$ of total sample or $29 \%$ of violent relationships, $n=189$ ), followed by mutually severe violence $(3.6 \%$ of total sample or $20 \%$ of violent relationships, $n=127$ ) and mild perpetration $(3.5 \%$ of total sample or $19 \%$ of violent relationships, $n=122$ ). There were significant differences in reporting of mutually severe violence by 
Table I. Occurrence of Relationship Violence Patterns in Total Sample and by Gender

\begin{tabular}{|c|c|c|c|c|}
\hline Relationship type & $\begin{array}{c}\text { Total sample } \\
\%(n)\end{array}$ & $\begin{array}{l}\text { Men } \\
\%(n)\end{array}$ & $\begin{array}{c}\text { Women } \\
\%(n)\end{array}$ & $\chi_{(1)^{2}}$ \\
\hline Nonviolent & $81.6(2,872)$ & $85.2(1,472)$ & $78.1(1,400)$ & \\
\hline Violent (Any) & $18.4(646)$ & $14.8(255)$ & $21.9(392)$ & $29.65^{* * *}$ \\
\hline \multicolumn{5}{|l|}{ Violence patterns } \\
\hline Mutually severe & $3.6(127)$ & $2.5(44)$ & $4.6(83)$ & $10.97^{* * *}$ \\
\hline Mutually mild & $5.4(189)$ & $4.7(81)$ & $6.1(108)$ & 3.11 \\
\hline Severe victim & $2.4(86)$ & $3.0(51)$ & $1.9(35)$ & $3.90^{*}$ \\
\hline Severe perpetration & $<1.0(32)$ & $<1.0(2)$ & $1.6(29)$ & - \\
\hline Mild victim & $2.6(90)$ & $2.1(37)$ & $3.0(53)$ & 2.49 \\
\hline Mild perpetration & $3.5(122)$ & $2.3(39)$ & $4.7(83)$ & $14.82^{* * *}$ \\
\hline
\end{tabular}

Note. Separate Chi Square analyses were conducted to compare gender differences in rates of nonviolent versus any type of violent relationship, and gender differences in rates for each pattern of violent relationship. Because of the small number of severe violence perpetrating men, this group was omitted from analysis of gender differences in reports of severe perpetration.

${ }^{*} p<.05$ (marginal). ${ }^{* *} p<.01 .{ }^{* * *} p<.001$.

men $(2.5 \%, n=44)$ and women $(4.6 \%, n=83)$, and similar differences were found in mild perpetration reported by men $(2.3 \%, n=39)$ and women $(4.7 \%, n=83)$. The least commonly reported violence was severe perpetration $(<1.0 \%$ of total sample or $5 \%$ of violent relationships, $n=32$ ), where it appears more women $(1.6 \% ; n=29)$ than men $(.9 \%$; $n=2$ ) reported performing such violence. However, as stated above, we did not statistically test this difference. Other findings showed that men reported being the victim of severe violence $(3.0 \% ; n=51)$ more frequently than women $(1.9 \% ; n=35)$; but, this difference was only marginally significant. Importantly, women reported being victims of severe violence more frequently than men reported perpetrating severe violence. To summarize, women reported receiving and performing more violence than men. About half of the violent relationships were characterized by mutual violence and the other half were one-sided violence. More than $60 \%$ of those in violent couples reported only mild violence, while $38 \%$ of those in violent couples reported severe violence.

\section{Association of Violence Patterns With Psychosocial Outcomes in Men and Women}

Prior to main study analysis, we conducted preliminary descriptive analyses of psychosocial outcome variables. These analyses revealed differences in distress and marital satisfaction between men and women in both nonviolent and violent relationships (see Table II). Considering those individuals in

Table II. Mean Differences in Psychological Distress and Marital Satisfaction Between Men and Women in Nonviolent and Violent Relationships

\begin{tabular}{|c|c|c|c|c|c|c|}
\hline \multirow[b]{2}{*}{ Relationship type } & \multicolumn{2}{|c|}{ Distress } & \multirow[b]{2}{*}{$p$} & \multicolumn{2}{|c|}{ Marital Satisfaction } & \multirow[b]{2}{*}{$p$} \\
\hline & $\begin{array}{c}\text { Men } \\
M(S E)\end{array}$ & $\begin{array}{l}\text { Women } \\
M(S E)\end{array}$ & & $\begin{array}{c}\text { Men } \\
M(S E)\end{array}$ & $\begin{array}{l}\text { Women } \\
M(S E)\end{array}$ & \\
\hline $\begin{array}{l}\text { Nonviolent } \\
\text { Violence patterns }\end{array}$ & $-.31(.02)$ & $-.15(.03)$ & .000 & $2.59(.02)$ & $2.53(.02)$ & .010 \\
\hline Mutual severe & $.10(.18)$ & $.47(.16)$ & .046 & $1.87(.11)$ & $1.80(.12)$ & .586 \\
\hline Mutual mild & $.31(.13)$ & $.77(.12)$ & .002 & $1.97(.09)$ & $1.80(.09)$ & .099 \\
\hline Severe victim & $.38(.15)$ & $1.36(.19)$ & .000 & $2.05(.12)$ & $1.27(.16)$ & .000 \\
\hline Severe perpetrator & - & $.70(.23)$ & - & - & $2.02(.11)$ & - \\
\hline Mild victim & $-.09(.16)$ & $.62(.17)$ & .001 & $2.34(.10)$ & $1.56(.11)$ & .000 \\
\hline Mild perpetrator & $.50(.18)$ & $.39(.12)$ & .546 & $2.41(.09)$ & $2.26(.08)$ & .257 \\
\hline
\end{tabular}

Note. This table presents gender differences in distress and marital satisfaction within each relationship type (i.e., nonviolent and the six patterns of violent relationships). Because of the small number of severe violence perpetrating men, results for this group are not reported. Because of the large sample size and number of comparisons, we consider $p<.01$ as representing statistically significant mean differences between men and women, as indicated by the least squares mean procedure with adjusted $t$ comparisons. 
nonviolent relationships, women had higher levels of distress $(M=-.15)$ than men $(M=-.31)$, and men reported greater marital satisfaction than women $(M=2.59$ vs. $M=2.43)$. Of those in violent relationships, women in severe or mild victim roles also had higher levels of distress than men (women severe victim $M=1.36$ vs. men severe victim $M=.38$; women mild victim $M=.62$ vs. men mild victim $M=-.09$ ). Similar differences were found for marital satisfaction; women victims reported lower levels of marital satisfaction than men (women severe victim $M=$ 1.27 vs. men severe victim $M=2.05$; women mild victim $M=1.56$ vs. men mild victim $M=2.34$ ). Although it seemed that men and women with any pattern of violence were worse off than the nonviolent in terms of psychosocial outcomes, women were worse off than men even when in nonviolent relationships. These findings suggested overall differences between men and women that may not be accounted for by intimate partner violence. Indeed, several past studies have found evidence for general patterns of gender differences in reports of mental health (e.g., Almeida \& Kessler, 1998; Davis, Matthews, \& Twamley, 1999; Kessler, 2000). Therefore, in subsequent analyses we used nonviolent men and women as a reference group to which all violence groups were compared, in order to control for baseline levels of the dependent variables. In addition, we statistically controlled for the main effect of gender when examining violence pattern $\mathrm{X}$ gender interactions. The results of our main analysis below, then, reveal associations between violence and psychosocial outcomes after considering the potential differences between men and women attributable to gender alone.

In order to examine the associations between violent relationship patterns and psychosocial outcomes in men and women, we conducted multiple linear regression analyses examining the main effects of violence and gender, as well as their interactions. First, the six dichotomous patterns of violence and gender were entered simultaneously into the regression models predicting psychological distress and marital satisfaction, followed by the six interaction terms of violence patterns by gender. Table III depicts results for both psychosocial outcomes. As shown, for distress, significant main effects were indicated for all violence patterns and gender. Individuals with these patterns of violent relationships had higher levels of distress than their nonviolent counterparts, and women had overall higher levels of distress than men. Results for the interaction of violence pattern by gender indicated significance for severe victimization only $(b=.78, S E=.28$, $p<.01)$. For marital satisfaction, significant main effects were found for gender and all violence patterns except for mild perpetration. Individuals with these patterns of violent relationships had lower levels of marital satisfaction than their nonviolent counterparts, and women had lower satisfaction than men. In addition, significant violence pattern by gender interactions were found for both mild $(b=-.68, S E=.26, p<.01)$ and severe $(b=-.68$, $S E=.17, p<.001)$ victimization.

To further explicate these findings between men and women, we conducted regression analyses examining the association of violence patterns with psychosocial outcomes stratified by gender. These regression analyses were run with the six patterns of violent relationships as independent variables, predicting psychological distress and marital satisfaction, separately in men and women. Tables IV and V present results of these stratified analyses estimating the magnitude of association for both distress and marital satisfaction, adjusted for age, education, income, employment status, and race. Considering distress, results showed that women had significantly more distress when involved in severe victimizing relationships than men. Results for marital satisfaction revealed that women had significantly lower levels of marital satisfaction when involved in either mild or severe victimizing relationships as compared with men.

To summarize the findings for psychosocial factors, it appeared that some patterns of violence (e.g., mild mutual) were consistently and similarly related to psychosocial outcomes for both genders. However, women experienced greater detriment to their distress and marital satisfaction when involved in victimizing relationships than men; victimization of any severity was significantly more psychosocially harmful for women than men. In fact, as depicted by the stratified analyses, mild victimization was related to neither distress nor marital satisfaction in men. In addition, stratified analyses indicated all patterns of violence were significantly associated with psychosocial sequelae in women, except that women's mild perpetration was not related to their reported levels of marital satisfaction. Thus, although the main effects model indicated that psychosocial outcomes were related to violence for both genders, men and women differed somewhat in the specific pattern and the magnitude of association. When this occurred, women experienced greater detriments to psychosocial health than men. 
Table III. Results of Multiple Linear Regression Models of Main Effects and Interactions of Violence Patterns and Gender Predicting Distress and Marital Satisfaction

\begin{tabular}{|c|c|c|c|c|c|c|}
\hline & \multicolumn{3}{|c|}{ Distress } & \multicolumn{3}{|c|}{ Marital Satisfaction } \\
\hline & $b$ & $(S E)$ & $\beta$ & $b$ & $(S E)$ & $\beta$ \\
\hline Base model & \multicolumn{3}{|c|}{$R^{2=} .060$} & \multicolumn{3}{|c|}{$R^{2=} .033$} \\
\hline \multicolumn{7}{|l|}{ Main effects Model } \\
\hline Mutual severe (ms) & $.47 * *$ & $(.15)$ & .09 & $-.66^{* * *}$ & $(.12)$ & -.18 \\
\hline Mutual mild (mm) & $.69 * * *$ & $(.13)$ & .16 & $-.67 * * *$ & $(.11)$ & -.22 \\
\hline Severe victim (sv) & $.96 * * *$ & $(.14)$ & .16 & $-.82 * * *$ & $(.14)$ & -.19 \\
\hline Severe perpetrator (sp) & - & $(-)$ & - & - & $(-)$ & $(-)$ \\
\hline Mild victim (mv) & $.48 * *$ & $(.18)$ & .08 & $-.66 * * *$ & (.13) & -.08 \\
\hline Mild perpetrator (mp) & $.55^{* * *}$ & (.14) & .10 & $-.22 *$ & $(.09)$ & -.15 \\
\hline Gender $(\mathrm{g})$ & $.18^{* * *}$ & $(.04)$ & .09 & $-.10 * *$ & $(.04)$ & -.07 \\
\hline Interaction Model & \multicolumn{3}{|c|}{$\Delta R^{2=} .078 * * *$} & \multicolumn{3}{|c|}{$\Delta R^{2=} .132 * * *$} \\
\hline Mutual severe (ms) & .36 & $(.19)$ & .07 & $-.68 * * *$ & $(.11)$ & -.19 \\
\hline Mutual mild (mm) & $.55^{* * *}$ & $(.17)$ & .13 & $-.62 * * *$ & $(.16)$ & -.20 \\
\hline Severe victim (sv) & $.65^{* * *}$ & $(.15)$ & .10 & $-.54 * *$ & $(.17)$ & -.13 \\
\hline Severe perpetrator $(\mathrm{sp})$ & - & $(-)$ & - & - & $(-)$ & - \\
\hline Mild victim (mv) & .18 & $(.23)$ & .03 & -.26 & $(.15)$ & -.06 \\
\hline Mild perpetrator (mp) & $.73 * * *$ & $(.23)$ & .14 & -.17 & $(.11)$ & -.05 \\
\hline Gender $(\mathrm{g})$ & $.13^{* * *}$ & $(.04)$ & .07 & -.06 & $(.04)$ & -.05 \\
\hline $\mathrm{ms} \times \mathrm{g}$ & .19 & $(.27)$ & .03 & .01 & $(.21)$ & .00 \\
\hline $\mathrm{mm} \times \mathrm{g}$ & .25 & $(.23)$ & .05 & -.10 & $(.21)$ & -.02 \\
\hline $\mathrm{sv} \times \mathrm{g}$ & $.78 * *$ & $(.28)$ & .08 & $-.68 * *$ & $(.26)$ & -.10 \\
\hline $\mathrm{sp} \times \mathrm{g}$ & - & $(-)$ & - & - & $(-)$ & - \\
\hline $\mathrm{mv} \times \mathrm{g}$ & .53 & $(.32)$ & .07 & $-.68 * * *$ & (.17) & -.12 \\
\hline \multirow{2}{*}{$\mathrm{mp} \times \mathrm{g}$} & -.25 & $(.29)$ & -.04 & -.07 & $(.15)$ & -.02 \\
\hline & \multicolumn{3}{|c|}{$\Delta \mathrm{R}^{2=.007 * * *}$} & \multicolumn{3}{|c|}{$\Delta R^{2=} .017 * * *$} \\
\hline
\end{tabular}

Note. Because of the small number of severe violence perpetrating men, results for this group are not reported. Findings reported here are results of regression analysis examining the main effects of violence patterns and gender and the interactions of violence and gender. The nonviolent relationships were used as the reference group (i.e., left out of the equation) with which to compare levels of distress and marital satisfaction. All regression analyses statistically controlled for age, education, income, race, and employment status. $\Delta R^{2}$ represents amount of change in variance when main effects were added to the base model of just covariates and when the interactions were added to the model of covariates and main effects. Because of the large sample size and the multiple models tested, we consider statistical significance to be $p<.01$.

${ }^{*} p<.05$ (marginal). ${ }^{* *} p<.01 .{ }^{* * *} p<.001$.

Table IV. Results of Multiple Linear Regression Model of Violence Patterns Predicting Psychological Distress Stratified by Gender

\begin{tabular}{|c|c|c|c|c|c|c|}
\hline & \multicolumn{3}{|c|}{ Men } & \multicolumn{3}{|c|}{ Women } \\
\hline & $b$ & $(S E)$ & $\beta$ & $b$ & $(S E)$ & $\beta$ \\
\hline Base model & \multicolumn{3}{|c|}{$R^{2}=.075$} & \multicolumn{3}{|c|}{$R^{2}=.056$} \\
\hline \multicolumn{7}{|l|}{ Relationship pattern } \\
\hline Mutual severe & $.38^{*}$ & (.19) & .07 & $.50 * * *$ & $(.20)$ & .10 \\
\hline Mutual mild & $.51 * *$ & (.18) & .12 & $.83 * * *$ & (.18) & .19 \\
\hline Severe victim & $.65^{* * *}$ & (.14) & .13 & $1.43 * * *$ & (.23) & .19 \\
\hline Severe perpetrator & - & $(-)$ & - & $.76^{* *}$ & $(.25)$ & .09 \\
\hline Mild victim & .18 & (.24) & .03 & $.72 * *$ & $(.23)$ & .12 \\
\hline \multirow[t]{2}{*}{ Mild perpetrator } & $.67 * *$ & $(.25)$ & .11 & $.47 * *$ & (.18) & .10 \\
\hline & \multicolumn{3}{|c|}{$\Delta R^{2}=.043^{* * *}$} & \multicolumn{3}{|c|}{$\Delta R^{2}=.095^{* * *}$} \\
\hline
\end{tabular}

Note. Because of the small number of severe violence perpetrating men, results for this group are not reported. Findings reported here are results of regressions conducted separately for men and women, using the six violence patterns as independent variables. The nonviolent relationships were used as the reference group (i.e., left out of the equation) with which to compare levels of distress. All regression analyses statistically controlled for age, education, income, race, and employment status. $\Delta R^{2}$ represents amount of change in distress variance when violence patterns were added to the base model of just covariates. Because of the large sample size and the multiple models tested, we consider statistical significance to be $p<.01$.

$* p<.05$ (marginal). ${ }^{* *} p<.01 .{ }^{* * *} p<.001$. 
Table V. Results of Multiple Linear Regression Model of Violence Patterns Predicting Marital Satisfaction Stratified by Gender

\begin{tabular}{|c|c|c|c|c|c|c|}
\hline & \multicolumn{3}{|c|}{ Men } & \multicolumn{3}{|c|}{ Women } \\
\hline & $b$ & $(S E)$ & $\beta$ & $b$ & $(S E)$ & $\beta$ \\
\hline Base model & \multicolumn{3}{|c|}{$R^{2}=.024$} & \multicolumn{3}{|c|}{$R^{2}=.052$} \\
\hline \multicolumn{7}{|l|}{ Relationship pattern } \\
\hline Mutual severe & $-.69 * * *$ & $(.11)$ & -.18 & $-.64 * * *$ & $(.17)$ & -.18 \\
\hline Mutual mild & $-.61 * * *$ & (.16) & -.21 & $-.71 * * *$ & $(.15)$ & -.23 \\
\hline Severe victim & $-.54 * * *$ & (.16) & -.15 & $-1.22 * * *$ & $(.20)$ & -.23 \\
\hline Severe perpetrator & - & $(-)$ & - & $-.47 * * *$ & $(.12)$ & -.08 \\
\hline Mild victim & -.26 & $(.15)$ & -.06 & $-.93 * * *$ & (.13) & -.22 \\
\hline \multirow[t]{2}{*}{ Mild perpetrator } & -.16 & $(.12)$ & -.04 & $-.24 *$ & $(.12)$ & -.07 \\
\hline & \multicolumn{3}{|c|}{$\Delta R^{2}=.108^{* * *}$} & \multicolumn{3}{|c|}{$\Delta R^{2}=.160^{* * *}$} \\
\hline
\end{tabular}

Note. Because of the small number of severe violence perpetrating men, results for this group are not reported. Findings reported here are results of regressions conducted separately for men and women, using the six violence patterns (i.e., six dichotomous variables) as independent variables. The nonviolent relationships were used as the reference group (i.e., left out of the equation) with which to compare levels of marital satisfaction. All regression analyses statistically controlled for age, education, income, race, and employment status. $\Delta R^{2}$ represents amount of change in marital rating variance when violence patterns were added to the base model of just covariates. Because of the large sample size and the multiple models tested, we consider statistical significance to be $p<.01$.

$* p<.05$ (marginal). ${ }^{* *} p<.01 . * * * p<.001$.

\section{Post Hoc Analyses: Are There Individuals Relatively "Happy" Despite the Violence?}

Victimization was associated with negative psychosocial outcomes but significantly more so for women than for men. In fact, men's violence patterns had slightly fewer associations with psychosocial problems than women as suggested by the stratified analyses. However, no significant gender differences emerged for associations between mutual violence and psychosocial outcomes, suggesting men and women experienced mutual violence similarly. Based on our findings of gender differences in some instances and gender similarities in others, we became interested in the full range of psychosocial experiences of men and women involved in violent relationships. Subsequently we decided to ask the post hoc question of whether some individuals could be relatively satisfied or happy despite the violence. We examined this question in an exploratory way, offering only descriptive analysis of highly satisfied and nondistressed individuals and the patterns of violent relationships in which they are involved. As these post hoc analyses were exploratory, we made no specific predictions as to which patterns of violence would be found to have more positive psychosocial outcomes.

The idea that some individuals in violent relationships could be happy despite violence is relatively new and yet to be tested, to our knowledge. To date, much research on mutual violence and other patterns in more general populations has focused on partners presenting at clinics for therapy (e.g., Vivian \& Langhinrichsen-Rohling, 1994), indicating a potential negative bias in distress and marital satisfaction couples experience. If violent couples satisfied with their relationships exist, they would probably not be represented in a clinical sample, but would exist in the type of national sample used in this study. We suspect that some individuals might be "happy" or satisfied with their relationships that include violence, and therefore exhibit high marital satisfaction and low levels of distress. In support of this supposition, prior informal interviews have suggested some couples may enjoy relationships with high levels of "passion"-with "passion" being associated with violence as well as sexuality (see Frieze, 2005). In addition, others have put forth the argument that mutual mild violence is common and that, in these relationships, violence might not be a way to control the partner as much as it is a way to gain control over a situation or argument (Johnson, 1995). Further, mutual violence, even if severe, may imply a kind of symmetry in the relationship. Thus, we examine post hoc the possibility that there are some individuals "happy," despite being a partner in a violent relationship. However, one caveat about this investigation is that we are unable to determine if mutual violence is truly mutual or is so 
only because one partner is acting in self-defense. Theoretically, we may find defensively mutually violent individuals represented in the lowest extreme on psychosocial outcomes - among those extremely distressed with negative relationship perceptions.

To explore whether some are happy in their violent relationships, as well as some who are extremely unhappy, we focused on individuals with extreme scores on psychosocial outcomes. For this analysis, we first presumed those who reported relationships as "excellent" were relatively satisfied with their relationships, whereas those who described relationships as "poor" were not at all satisfied. In addition, we took the bottom third and top third of the distress scores, identifying the former as "no" distress and the latter as "high" distress. We examined those who reported relationships as "excellent" or "poor," and the two distress groups for their involvement in the patterns of violent relationships.

Results revealed that $27 \%(n=174)$ of those in violent relationships reported that their relationships as excellent. Of those reporting excellence, $29.6 \%$ were in mutually mild and $16.2 \%$ were in mutual severe relationships. In addition, $27.2 \%$ were involved in mild perpetration, while the others were distributed throughout the other patterns. Considering distress, of those in violent relationships who were categorized as "no" distress $(n=$ 214 ), $26.3 \%$ were in mutually severe violent relationships and $25.5 \%$ in mutually mild relationships. In addition, $19.3 \%$ were mild violence perpetrators, while others were distributed throughout the other patterns. Of those at the other extreme, reporting "poor" relationships $(n=46), 43.1 \%$ were in mutually mild violent relationships and $21.9 \%$ were in severe victimizing relationships. Of those considered "high" distress $(n=217), 30.7 \%$ were in mutually mild and $18.3 \%$ in mutually severe relationships. In addition, $17.8 \%$ were mild violence perpetrators, while others were distributed throughout the other patterns.

Thus, there appeared to be a range of possible psychosocial experiences among individuals in various patterns of violent relationships. Overall individuals within violent relationships experienced negative outcomes (as shown in our main findings), but there was evidence that not everyone in violent relationships had these negative reactions. These exploratory post hoc analyses further showed that those relatively "satisfied" in their violent relationships were distributed across different patterns of violence. Many satisfied individuals seemed to be involved in mutual violence; yet, many other individuals with mutually mild forms of violence appeared extremely unhappy. Due to the preliminary nature of these findings we offer no definitive conclusions but do discuss results further.

\section{DISCUSSION}

The present study examined violent relationships by classifying violence patterns in a national sample of men and women, and exploring the differential association of these patterns with psychosocial outcomes in men and women. Overall, results showed that the most common form of violence was mutually mild, followed by mutually severe. Significantly more women reported severe mutual violence and mild perpetration, while men reported slightly more severe victimization than women (although this difference was only marginally significant, $p<.05$ ). Results of main analyses revealed that women victims of violence had significantly more distress and greater detriments to marital satisfaction than men. This was true regardless of the severity of the onesided violence received by the partner. Interestingly, there seemed to be some gender similarities in terms of psychosocial associations with mutually violent relationships. In addition, we found preliminary evidence that some individuals could be relatively "satisfied" despite violent relationships.

Rates of violence patterns in our study have application to the existing violence literature. First, the most frequent pattern of violent relationship in this study was mild violence perpetrated by both partners (i.e., mutual). This finding is in-line with Johnson's typology, as our most common mutually mild group is similar to his category of common couple violence. Yet, we found in the national sample a large number of individuals in mutually severe violent relationships, as well as one-sided severe victimization. Johnson $(1995,2001)$ has argued that in order for researchers to get the best depiction of common couple violence and intimate terrorism, they must sample from different populations. According to this position, intimate terrorism would best be accessed by way of battered women's shelters, whereas the more common, mutual form would best be tapped via community samples (Johnson, 1995). In fact, recent work provides support for some violence patterns being more prevalent in certain populations such as shelters and other patterns being seen more in general populations of men and women (Graham-Kevan \& Archer, 2003). However, our 
finding of a range of violent acts performed by men and women in a national sample supports Olson's (2002) conclusion that common couple violence may not be a "unitary phenomenon" and Anderson's (2002) findings of different patterns of violent relationships (male-to-female, female-to-male, mutual) in a national sample. Unfortunately, our data did not allow us to examine coercive control, one identifying factor of Johnson's typology, so we can neither corroborate nor disconfirm his patterns precisely.

Second, that more women reported perpetrating violence than men, and slightly more men reported being the victim of severe violence than women (although only a marginally significant difference), may challenge assumptions about women's victimization in relationships. One potential explanation for these findings is that women experiencing violence from partners are more likely than men to retaliate partner violence. If true, women in such retaliatory relationships would be classified into mutual violence categories, not as victims. In support of this possibility, more women than men reported severe mutual violence, and results of our post hoc analyses provide partial support that some individuals in mutually violent relationships may be violent in an attempt to defend themselves (as shown by their extreme distress and low marital ratings). Another potential explanation for gender differences in victimization and perpetration rates is a reporting bias in men's reports of perpetration. Some researchers have argued men's violence is not as socially acceptable as women's violence, and so men may be unwilling to report perpetrating violent acts (e.g., Felson, 2002; Astin, Redston, \& Campbell, 2003). In our study women did report higher levels of victimization than men reported perpetrating. But, if men's low rates of severe perpetration do represent a bias in their reporting, then their relationships would likely be characterized as asymmetric (in favor of their partners being more violent) or even nonviolent. Yet, women's perpetration and men's victimization rates in this study were relatively equivalent. Further, individual men and women in our sample were not couples, but rather individuals reporting their own and their partners' behaviors, which could partially explain discrepancies in reports. Thus, we cannot make definitive conclusions about rates of patterns between men and women. However, our study provides evidence that a range of violent behaviors performed by both genders are present in large, national samples, and that researchers can use such data to examine violence patterns, but that it may be necessary for future researchers to devise ways of over-sampling severely violent men.

Overall, our main findings indicate that we cannot take a general, non-gendered approach to the study of intimate partner violence. Some distinctions in violence patterns translate into meaningful differences in their experience for men and women. The most striking and consistent finding is that victimization is associated with significantly more negative psychosocial outcomes for women than men. These results for women support a long line of past research on abused women and negative sequelae they experience (Browne, 1993; Golding, 1999; Goodman et al., 1993; Janoff-Bulman \& Frieze, 1983; Marshall, 1999; Williams \& Mickelson, 2004). As such, findings of the present study reinforce the importance of continued research and advocacy concerning women abused by their male partners.

It is less clear why the psychosocial variables used in this research were not as strongly associated with victimization for men as for women. Although victimization had some significant associations with distress and marital satisfaction for men, these associations were significantly weaker than they were for women, and mild victimization was not significantly related to distress or marital satisfaction for men in stratified analyses. It may be, as others have speculated, that men do not take women's violence seriously (Sinclair \& Frieze, 2002). Another possibility is that we are not addressing the variables that would tap men's experience of violence victimization. Perhaps men have different psychosocial factors involved with violence, including fear of loss of custody of their children, alcohol abuse, or anger. As such, men may experience other negative effects of women's violence, but researchers simply are not asking the right questions. Future research should expand the scope of variables associated with violence. In addition, because so little research on men's victimization exists, more qualitative study designs (e.g., focus groups) might serve as a preliminary step toward understanding variables associated with intimate partner violence. Yet, violence patterns did show some significant relations with distress and marital satisfaction for men indicating that additional research is needed in the area of men's experiences of partner violence.

Whereas victimization-whether mild or severe-was experienced differently by men and women, other findings for violence patterns suggested gender similarities and warrant additional 
research. For example, symmetric violence patterns appeared to be experienced similarly by both genders. Stratified analyses showed that mild mutual violence patterns were significantly associated with distress and less marital satisfaction for men and women, while severe mutual violence was related to lower marital satisfaction for both genders but was linked with distress in women only. These findings may be important considering that some research has shown mutually violent couples, particularly those perpetrating mild violence toward each other, to be quite common. Indeed, mutually violent relationships were the most common patterns found in our examination of the national sample. Despite the seemingly mild nature of violence and its mutuality between partners, both men and women experienced psychosocial problems when involved in these patterns of relationships. As such, it may be necessary to interpret the commonality of this violence as problematic. More research is clearly needed on mild and severe mutually violent relationships and how both partners in the relationship experience them.

Yet, our post hoc speculations about potentially "happy" individuals resulted in interesting preliminary findings that should be followed up with future research. We found evidence that some individuals may be satisfied despite their violent relationships. This finding highlights several questions about who these individuals are and how they differ from those with negative psychosocial outcomes following violence. Perhaps men and women not distressed in these relationships have thrill-seeking personalities or highly passionate relationships in which severe violence is only one component (see Borochowitz \& Eisikovits, 2002, for analysis of love in violent relationships). Or, perhaps there are other facets of the relationship that should be used to delineate violence patterns. However, the preliminary nature of our post hoc findings prohibits us from making conclusions about satisfaction or "happiness" associated with violence. In addition, our analyses showed there are still numbers of individuals unhappy with violent relationships, reflecting that some may be violent in self-defense. Moreover, analyses indicated many patterns of violence were significantly different on psychosocial outcomes than the nonviolent; those with violence had more distress and less marital satisfaction than their nonviolent counterparts. Thus, although some may be satisfied and go without distress, the nonviolent may still fair best psychosocially. Future studies might extend this research by examining correlates of satisfaction within violent relationships.
Overall, we believe researchers must continue becoming more specific in questions asked about patterns of violent behaviors and processes. We need more information on how violent relationships develop over time, when and how they change, and how processes vary by individual differences in couples.

\section{Limitations}

It is necessary to acknowledge some limitations of the present study attributable to the nature of the NCS data used to conduct secondary analysis. Even though the data represent the U.S. population, the sub-sample with violence we examined may not. The method used to assess relationship violence may have contributed to underestimates of violence. For example, a full range of violent behaviors (e.g., stalking, coercive control) was not assessed. A crucial next step is for future nationally representative studies to assess multiple forms of violent acts performed by men and women alike to more fully capture violent relationships, especially in light of the general dearth of empirical research on female violence and male victimization. In addition, married or cohabiting respondents reported their own and their partners behaviors. Some researchers have argued that, "reliance on either batterers or their victims as sole informants on their spouse/partner threatens the reliability and validity of the information" (Rosenbaum, Geffner, \& Benjamin, 1997, p. 74). Because only one partner of the couple was interviewed we also could not determine the distress or marital satisfaction of the relationship partner. Future work would benefit from extending reports to assess both partners of the couple, and couples of different sexual orientations. More generally, self-reports used in this study (as in many studies) could underestimate the extent to which violence was used in the relationship, especially severe perpetrated violence, and have implications for the strength of association between violence and adjustment. Related, the psychosocial items were not asked specifically in relation to respondents' partner violence experience. Future research on the relations put forth in this cross-sectional study could address more completely the psychosocial impact of violence patterns using longitudinal designs.

\section{ACKNOWLEDGMENTS}

The authors would like to thank Dr Lisa Brush and the anonymous reviewers for their helpful 
comments on an earlier draft of this manuscript. The NCS was funded by the National Institute of Mental Health (Grants R01 MH/DA46376 and R01 MH49098), the National Institute of Drug Abuse (through a supplement to R01 MH/DA46376) and the W. T. Grant Foundation (Grant 90135190).

\section{REFERENCES}

Almeida, D. M., \& Kessler, R. C. (1998). Everyday stressors and gender differences in daily distress. Journal of Personality and Social Psychology, 75, 670-680.

Anderson, K. L. (2002). Perpetrator or victim? Relationships between intimate partner violence and well-being. Journal of Marriage and the Family, 64, 851-863.

Archer, J. (2000). Sex differences in aggression between heterosexual partners: A meta-analytic review. Psychological Bulletin, 126, 651-680.

Astin, S., Redston, P., \& Campbell, A. (2003). Sex differences in social representations of aggression: Men justify, women excuse? Aggressive Behavior, 29, 128-133.

Borochowitz, D. Y., \& Eisikovits, Z. (2002). To love violently: Strategies for reconciling love and violence. Violence Against Women, 8, 476-494.

Browne, A. (1993). Violence against women by male partners: Prevalence, outcomes, and policy implications. American Psychologist, 48, 1077-1087.

Davis, M. C., Matthews, K. A., \& Twamley, E. W. (1999). Is life more difficult on Mars or Venus? A meta-analytic review of sex differences in major and minor life events. Annals of Behavioral Medicine, 21, 83-97.

Felson, R. B. (2002). Violence \& gender reexamined. Washington, DC: American Psychological Association.

Frieze, I. H. (2005). Hurting the one you love: Violence in relationships. Belmont, CA: Thomson Wadsworth.

Frieze, I. H., \& Browne, A. (1989). Violence in marriage. In L. Ohlin \& M. Tonry (Eds.), Family Violence. (163-218). Chicago: University of Chicago Press.

Frieze, I. H., Hymer, S., \& Greenberg, M. S. (1987). Describing the crime victim: Psychological reactions to victimization. Professional Psychology: Research and practice, 318, 299-315.

Golding, J. M. (1999). Intimate partner violence as a risk factor for mental disorders: A meta-analysis. Journal of Family Violence, 14, 99-132.

Goodman, L., Koss, M. P., \& Russo, N. F. (1993). Violence against women: Physical and mental health effects: II. Research findings. Applied \& Preventive Psychology, 2, 79-89.

Graham-Kevan, N., \& Archer, J. (2003). Physical aggression and control in heterosexual relationships: The effect of sampling. Violence and Victims, 18, 181-196.

Janoff-Bulman, R., \& Frieze, I. H. (1983). A theoretical perspective for understanding reactions to victimization. Journal of Social Issues, 39, 1-17.

Johnson, M. P. (1995). Patriarchal terrorism and common couple violence: Two forms of violence against women. Journal of Marriage and the Family, 75, 283-294.

Johnson, M. P. (2001). Conflict and control: Symmetry and asymmetry in domestic violence. In A. Booth, A. C. Crouter, et al. (Eds.), Couples in Conflict (pp. 95-104). Mahwah, NJ: Erlbaum.

Katz, J., Kuffel, S. W., \& Coblentz, A. (2002). Are there gender differences in sustaining dating violence?: An examination of frequency, severity, and relationship satisfaction. Journal of Family Violence, 17, 247-271.

Kessler, R. C. (2000). Gender differences in major depression: Epidemiological findings. In E. Frank (Ed.), Gender and Its
Effects on Psychopathology (pp. 61-84). Washington, DC: American Psychiatric Publishing.

Kessler, R. C., McGonagle, K. A., Zhao, S., Nelson, C. B., Hughes, M., Eshleman, S., Wittchen, H.-U., \& Kendler, K. S. (1994). Lifetime and 12-month prevalence of DSM-III-R psychiatric disorders in the United States: Results from the National Comorbidity Survey. Archives of General Psychiatry, 51, 8-19.

Kimmel, M. S. (2002). 'Gender symmetry' in domestic violence: A substantive and methodological research review. Violence Against Women, 8, 1332-1363.

Langhinrichsen-Rohling, J., Schlee, K. A., Monson, C. M., Ehrensaft, M., \& Heyman, R. (1998). What's love got to do with it?: Perceptions of marital positivity in H-to-W aggressive, distressed, and happy marriages. Journal of Family Violence, 13, 197-212.

Lawrence, E., \& Bradbury, T. N. (2001). Physical aggression and marital dysfunction: A longitudinal analysis. Journal of Family Psychology, 15, 135-154.

Marshall, L. L. (1999). Effects of men's subtle and overt psychological abuse on low-income women. Violence and Victims, $14,69-88$.

Migliaccio, T. A. (2002). Abused husbands: A narrative analysis. Journal of Family Issues, 23, 26-52.

Olson, L. N. (2002). Exploring "common couple violence" in heterosexual romantic relationships. Western Journal of Communication, 66, 104-128.

Pagelow, M. D. (1981). Women-battering: Victims and their experiences. Beverly Hills, CA: Sage.

Pagelow, M. D. (1984). Family violence. New York: Praeger.

Plichta, S. B. (1996). Violence and abuse: Implications for women's health. In M. M. Falik \& K. S. Collins (Eds.), Women's Health: The Commonwealth Fund Survey (pp. 237272). Baltimore: The Johns Hopkins University Press.

Resnick, H. S., Acierno, R., \& Kilpatrick, D. G. (1997). Health impact of interpersonal violence: II. Medical and mental health outcomes. Behavioral Medicine, 23, 65-78.

Rosenbaum, A., Geffner, R., \& Benjamin, S. (1997). A biopsychosocial model for understanding relationship aggression. In R. Geffner, S. B. Sorenson, \& P. K. Lundberg-Love (Eds.), Violence and sexual abuse at home: Current issues in spousal battering and child maltreatment (pp. 57-79). New York: Haworth Press.

Rusbult, C. E. (1983). A longitudinal test of the investment model: The development (and deterioration) of satisfaction and commitment in heterosexual involvements. Journal of Personality and Social Psychology, 45, 101-117.

Rust, K. (1985). Variance estimation for complex estimators in sample surveys. Journal of Official Statistics, 1, 381-397.

Sinclair, H. C., \& Frieze, I. H. (2002). Initial courtship behavior and stalking: How should we draw the line? In K. E. Davis \& I. H. Frieze (Eds.), Stalking: Perspectives on victims and perpetrators (pp. 186-211). New York: Springer.

Straus, M. A. (1979). Measuring intrafamily conflict and violence: The Conflict Tactics (CT) Scales. Journal of Marriage and the Family, 41, 75-88.

Straus, M. A. (1999). The controversy over domestic violence by women: A methodological, theoretical, and sociology of science analysis. In X. B. Arriaga \& S. Oskamp (Eds.), Violence in Intimate Relationships (pp. 17-44). Thousand Oaks, CA: Sage.

Straus, M. A., \& Gelles, R. J. (1988). How violent are American families? Estimate from the National Family Violence Resurvey and other studies. In G. T. Hotaling, D. Finkelhor, J. T. Kirkpatrick, \& M. A. Straus (Eds.), Family abuse and its consequences: New directions in research (pp. 14-36). Newbury Park, CA: Sage.

Swan, S. C., \& Snow, D. L. (2003). Behavioral and psychological differences among abused women who use violence in intimate relationships. Violence Against Women, 9, 75-109. 
Testa, M., \& Leonard, K. E. (2001). The impact of marital aggression on women's psychological and marital functioning in a newlywed sample. Journal of Family Violence, 16, 115130.

Thibaut, J. W., \& Kelley, H. H. (1959). The social psychology of groups. Oxford: Wiley.

Tjaden, P., \& Thoennes, N. (1998). Prevalence, incidence, and consequences of violence against women. Findings from the National Violence Against Women survey. Washington, DC: National Institute of Justice.

U.S. Department of Health and Human Services. (1992). National Health Interview Survey, 1989 (Computer file). Hyattsville, MD: National Center for Health Statistics.

Vivian, D., \& Langhinrichsen-Rohling, J. (1994). Are bidirectionally violent couples mutually victimized? A gender- sensitive comparison. Violence and Victims, 9, 107124.

Walker, L. E. (1979). The battered woman. New York: Harper \& Row.

White, J. W., \& Kowalski, R. M. (1998). Violence against women: An integrative perspective. In R. G. Geen \& E. Donnerstein (Eds.), Perspectives on Human Aggression. New York: Academic Press.

White, J. W., Smith, P. H., Koss, M. P., \& Figueredo, A. J. (2000) Intimate Partner Aggression: What Have We Learned? Commentary on Archer's Meta-Analysis. Psychological Bulletin, 126, 690-696.

Williams, S. L., \& Mickelson, K. D. (2004). The nexus of domestic violence and poverty: Resilience in women's anxiety. Violence Against Women, 10, 283-293. 